\title{
Novel UWB BPF with a controllable notched band using hybrid structure
}

\author{
Xia Xinlin ${ }^{1 a)}$, Yu Liu ${ }^{1}$, Haodong Lin ${ }^{1}$, Tao Yang ${ }^{1}$, and Haiyan Jin ${ }^{2}$ \\ ${ }^{1}$ School of Electronic Engineering, University of Electronic Science and Technology \\ of China, No. 2006, Xiyuan Ave, West Hi-Tech Zone, Chengdu, 611731, China \\ ${ }^{2}$ School of Communication and Information Engineering, \\ University of Electronic Science and Technology of China, \\ No. 4, Section 2, North Jianshe Road, Chengdu, 610054, China \\ a)xxl0702@sina.cn
}

Abstract: In this letter, an ultra-wideband (UWB) bandpass filter (BPF) based on CPW-to-microstrip transition structure is proposed. To improve its selectivity, an interdigital coupled-line and split ring resonator (SRR) are used to generate two extra transmission zeros located at the lower and upper edge of the passband separately. The measured results show that the proposed filter possesses satisfactory performance such as compact size, sharp roll-off, and wide fractional bandwidth of 133\% $(2.35-11.75 \mathrm{GHz})$. Moreover, a notched band with deep attenuation introduced by coupling T-shaped short stub (CTSSS) is achieved to block the ITU8.0 band with centre frequency of $8.2 \mathrm{GHz}$. And the notched band is controllable. This filter can be a good candidate for ultra-wideband applications.

Keywords: bandpass filter (BPF), ultra-wideband (UWB), split ring resonator (SRR), coupling T-shaped short stub (CTSSS)

Classification: Microwave and millimeter-wave devices, circuits, and modules

\section{References}

[1] X. Chen, et al.: "UWB bandpass filter with sharp rejection and narrow notched band," Electron. Lett. 50 (2014) 1077 (DOI: 10.1049/el.2014.1420).

[2] H. D. Lin, et al.: "A novel ultra-wideband bandpass filter using defected microstrip structures," IEICE Electron. Express 13 (2016) 20160165 (DOI: 10. 1587/elex.13.20160165).

[3] K. Wang, et al.: "A compact UWB CPW bandpass filter with short-ended Hshaped resonator and controllable notched band," Microw. Opt. Technol. Lett. 55 (2013) 1577 (DOI: 10.1002/mop.27663).

[4] H. D. Lin, et al.: "Compact high selectivity UWB filter using composite CPWmicrostrip structure," IEICE Electron. Express 13 (2016) 20161049 (DOI: 10. 1587/elex.13.20161049).

[5] A. N. Ghazali, et al:: "A miniaturized microstrip-to-CPW transition based UWB-BPF with shaped roll-off and minimum insertion loss," Microw. Opt. Technol. Lett. 58 (2016) 289 (DOI: 10.1002/mop.29551).

[6] C.-H. Lee, et al.: "Band-notched ultra-wideband bandpass filter design using combined modified quarter-wavelength tri-section stepped-impedance resona- 
tor,” IET Microw. Antennas Propag. 3 (2009) 1232 (DOI: 10.1049/iet-map. 2008.0340).

[7] S. Pirani, et al:: "Band-notched UWB BPF design using parasitic coupled line," IEEE Microw. Wireless Compon. Lett. 20 (2010) 444 (DOI: 10.1109/LMWC. 2010.2049830).

[8] C.-H. Lee, et al.: "Band-notched balanced UWB BPF with stepped-impedance slotline multi-mode resonator," IEEE Microw. Wireless Compon. Lett. 22 (2012) 182 (DOI: 10.1109/LMWC.2012.2188019).

[9] J. Li, et al.: "Compact UWB BPF with notch band based on SW-HMSIW," Electron. Lett. 51 (2015) 1338 (DOI: 10.1049/el.2015.0449).

[10] H. Zhu, et al.: "Ultra-wideband bandpass filter with a notch-band using stubloaded ring resonator," IEEE Microw. Wireless Compon. Lett. 23 (2013) 341 (DOI: 10.1109/LMWC.2013.2262928).

[11] G. Karimi, et al.: "Compact UWB BPF using slotted resonator with an independently controllable notched band," Int. J. Microw. Wirel. Technol. 8 (2016) 25 (DOI: 10.1017/S1759078714001251).

\section{Introduction}

Since the US Federal Communication Commission (FCC) authorized the ultrawideband (UWB) spectrum (3.1 to $10.6 \mathrm{GHz}$ ) for commercial use in 2002, the UWB bandpass filter (BPF) has received countless interest. In the recent reported literatures, several methods and structures have been proposed to implement UWB BPF with compact size, sharp roll-off, low insertion loss and wide bandwidth [1, 2, $3,4,5,6,7,8,9,10,11]$. For example, the MMR [1], defected microstrip structure [2] and some transition structures have been widely used to design UWB BPF $[3,4,5]$. At the same time, to block some undesired signals such as WLAN $(5.2 \mathrm{GHz})$ and ITU8.0 $(8.2 \mathrm{GHz})$ in the passband of the UWB, various structures and methods have been proposed to obtain a notched band $[6,7,8,9,10,11]$. An L-shaped open-end slot was inserted in the TSSIR to generate a notch band at $5.5 \mathrm{GHz}$ [6]. In [7], to achieve a notched band that its centre frequency can be changed, a parasitic coupled line was added. An Ultra-wideband BPF based on a microstrip-to-slotline transition was presented in [8]. Besides, to reject the WLAN signals, a microstrip stub located at the feed-lines was adopted. In [9], a novel UWB BPF using SW-HMSIW with a notch band created by an L-type resonator was presented. Moreover, in recent years, some novel structures were reported to implement notch band such as the ring resonators [10] and the defected ground structure [11].

In this letter, a novel compact UWB BPF implemented by the hybrid microstrip (MS) and coplanar waveguide (CPW) is proposed. The interdigital coupled-line (ICL) and split ring resonator (SRR) are used to improve its selectivity. As a result, the proposed filter has more sharp selectivity comparing with some other traditional filters. Moreover, this filter achieves a notched band at $8.2 \mathrm{GHz}$ with a maximum rejection loss of $42 \mathrm{~dB}$. To verify the performance of the proposed UWB BPF, a filter prototype is fabricated and measured. 


\section{The design and analysis of this UWB BPF}

\section{A: Hybrid UWB BPF with improved selectivity}

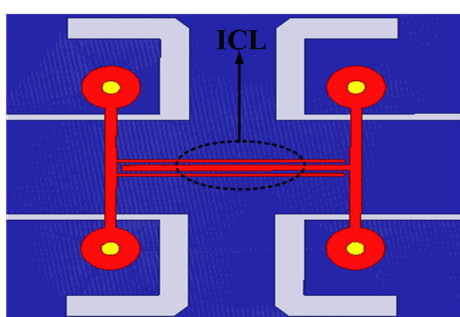

(a)

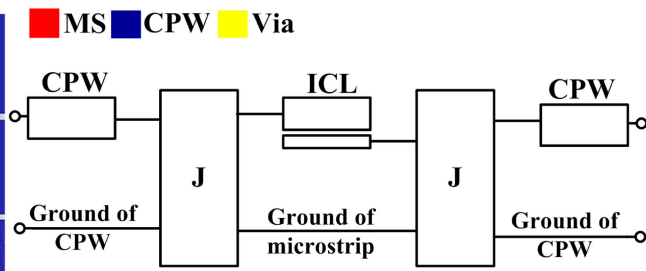

(b)

Fig. 1. (a) Layout of the CPW-MS-CPW with ICL, (b) Equivalent Jinverter network.

The basic structure of the proposed modified CPW-MS-CPW and its equivalent J-inverter network are given in Fig. 1(a) and Fig. 1(b), respectively. The ICL is simplified as an asymmetric parallel coupling line. As mentioned in [3], the J inverters are realized by the surface-to-surface coupling structure of CPW-tomicrostrip transition structure. In this work, the middle microstrip is replaced by an interdigital coupled-line. As the simulated results shown in Fig. 2(e), the modified CPW-MS-CPW with an interdigital coupled line structures (ICL) has four transmission zeros. Among them, $\mathrm{f}_{\mathrm{z} 3}$ is generated by CPW-MS-CPW, $\mathrm{f}_{\mathrm{z} 0}$ $(0 \mathrm{GHz})$ and $\mathrm{f}_{\mathrm{z} 2}$ are introduced by ICL. The transmission zero $\mathrm{f}_{\mathrm{z} 1}$ of Fig. 2(e) could be explained by its low frequency lumped model shown in Fig. 2.

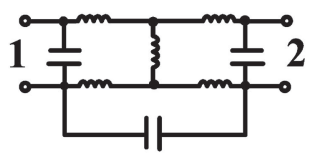

(a)

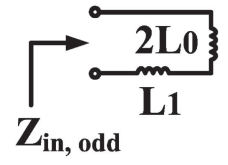

(c)

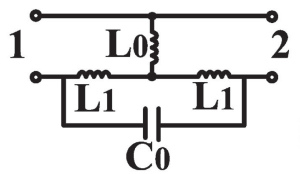

(b)

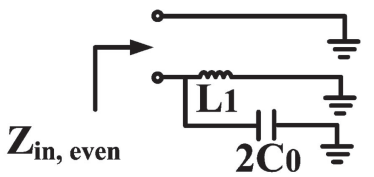

(d)

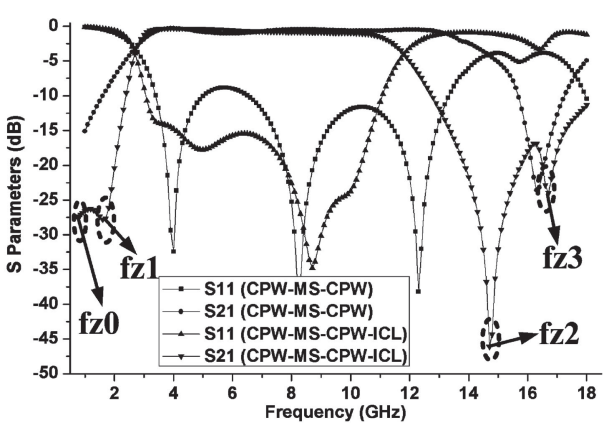

(e)

Fig. 2. (a) Equivalent low frequency lumped model, (b) Simplified model, (c) Odd-mode, (d) Even-mode, (e) Simulated results for traditional and modified CPW-MS-CPW.

For the odd-mode excitation, its input impedance $\left(Z_{\text {in,odd }}\right)$ could be obtained from Fig. 2(c) as shown in Eq. (1).

$$
\mathrm{Z}_{\text {in,odd }}=\mathrm{j} \omega\left(2 \mathrm{~L}_{0}+\mathrm{L}_{1}\right)
$$

For the even-mode excitation, its input impedance $\left(Z_{\text {in,even }}\right)$ could be obtained from Fig. 2(d) as shown in Eq. (2).

$$
Z_{\text {in,even }}=\frac{j \omega \mathrm{L}_{1}}{1-2 \omega^{2} \mathrm{~L}_{1} \mathrm{C}_{0}}
$$

The condition of generating a transmission zero $Z_{\text {in,odd }}=Z_{\text {in,even }}$ can be expressed by Eq. (3). And its solution is shown in Eq. (4).

$$
\omega^{2}=\frac{\mathrm{L}_{0}}{\mathrm{~L}_{1} \mathrm{C}_{0}\left(2 \mathrm{~L}_{0}+\mathrm{L}_{1}\right)}
$$




$$
\mathrm{f}_{\mathrm{z} 1}=\sqrt{\frac{\mathrm{L}_{0}}{\mathrm{~L}_{1} \mathrm{C}_{0}\left(2 \mathrm{~L}_{0}+\mathrm{L}_{1}\right)}} / 2 \pi
$$

From the above analysis, the modified CPW-MS-CPW could generate a transmission zero at low frequency by using an ICL. Moreover, the ICL can also introduce an extra transmission zero ( $f_{\mathrm{z} 2}$ in Fig. 2(e)) at high frequency. As a result, its selectivity is improved significantly, especially in low frequency. By contrast, the traditional CPW-MS-CPW without ICL has bad selectivity in both low- and high-frequency as the simulated results shown in Fig. 2(e).

\section{B: A UWB BPF with a deep notched-band}

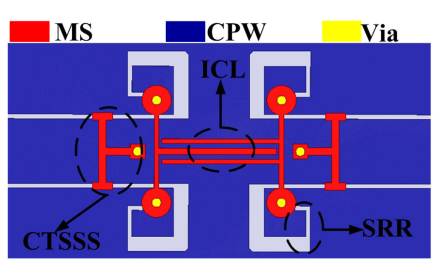

(a)

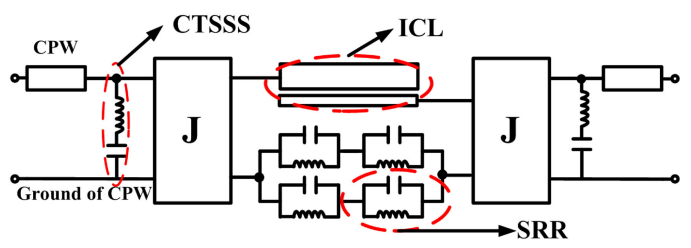

(b)
Fig. 3. Layout of the proposed UWB BPF. (b) Equivalent circuit for the UWB BPF.

In order to further improve its selectivity in high frequency, a split ring resonator (SRR) is used. The SRR could generate a transmission zero of $f_{z 4}$ shown in Fig. 4(a), and its equivalent circuit is a parallel LC resonator as shown in Fig. 3(b). In this work, a coupling T-shaped short stub (CTSSS) is applied to implement a notched band. The basic structure of the proposed UWB BPF with a notched band is shown in Fig. 3(a). As its equivalent circuit shown in Fig. 3(b), the CTSSS can be equivalent to a serial LC resonator. And the $\mathrm{J}$ inverters are realized by the CPW-to-microstrip transition structures.
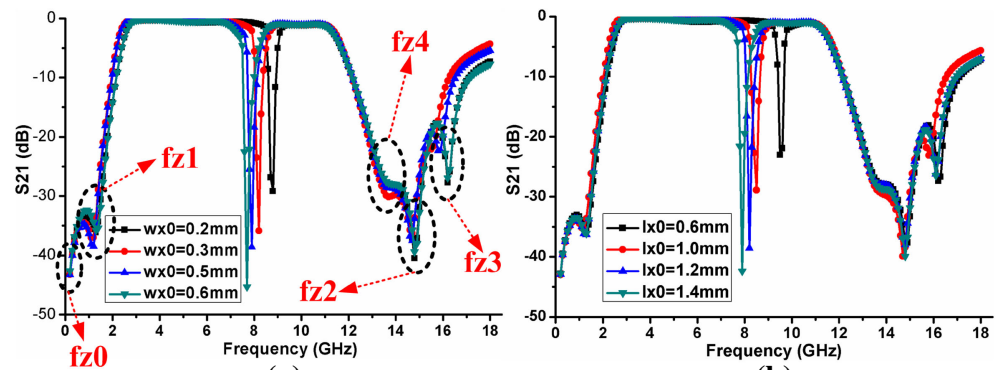

(a)

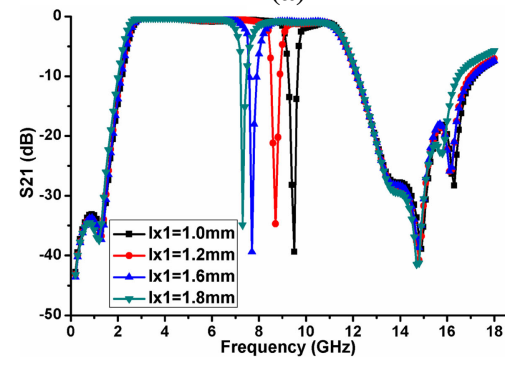

(c) (b)

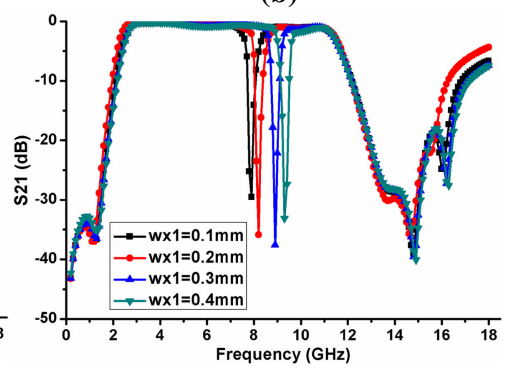

(d)
Fig. 4. Simulated results of this filter for several values (a) wx0, (b) $1 \times 0$, (c) $1 \times 1$, (d) wx1.

As the simulated S21 of the proposed UWB BPF with CTSSS for several wx0, $1 \mathrm{x} 0,1 \mathrm{x} 1$ and $\mathrm{wx} 1$ values shown in Fig. 4, the notched band is controllable. The frequency with maximum attenuation of notched band is $7.8,8.0,8.2$ and $8.8 \mathrm{GHz}$ 
for the case with wx 0 equal to $0.2,0.3,0.5$ and $0.6 \mathrm{~mm}$, respectively. The results show that a larger value of $1 \mathrm{x} 0$ or wx 0 give not only a lower notched-band centre frequency, but also a stronger attenuation and wider notched bands. In Fig. 4(c), the simulated insertion losses for $1 \mathrm{x} 1=1,1.2,1.6$ and $1.8 \mathrm{~mm}$ are plotted. Clearly, with the increase of $1 x 1$, the notched-band centre frequency is seen to decrease. And the parameter wx 1 is also found to have impact on the notched-band with the centre frequency change increasing nearly $0.8 \mathrm{GHz}$ as wx 1 increases from $0.1 \mathrm{~mm}$ to $0.4 \mathrm{~mm}$. In this work, to block the ITU8.0 band with centre frequency of $8.2 \mathrm{GHz}$, we choose $\mathrm{wx} 0=0.3 \mathrm{~mm}, \mathrm{wx} 1=0.2 \mathrm{~mm}, \mathrm{x} 0=1.1 \mathrm{~mm}$ and $1 \mathrm{x} 1=1.3 \mathrm{~mm}$.

As per the above-mentioned analysis, this filter has sharp selectivity and a deep notched band in the UWB. Finally, the proposed Ultra-wideband bandpass filter is designed and fabricated for verification. The substrate used in this work is the Rogers RO 4350, which has a relative permittivity of 3.66, loss tangent of 0.004 and the thickness of the substrate is $0.508 \mathrm{~mm}$. The photograph of the fabricated filter is shown in Fig. 5(b).

\section{Experimental results and discussion}

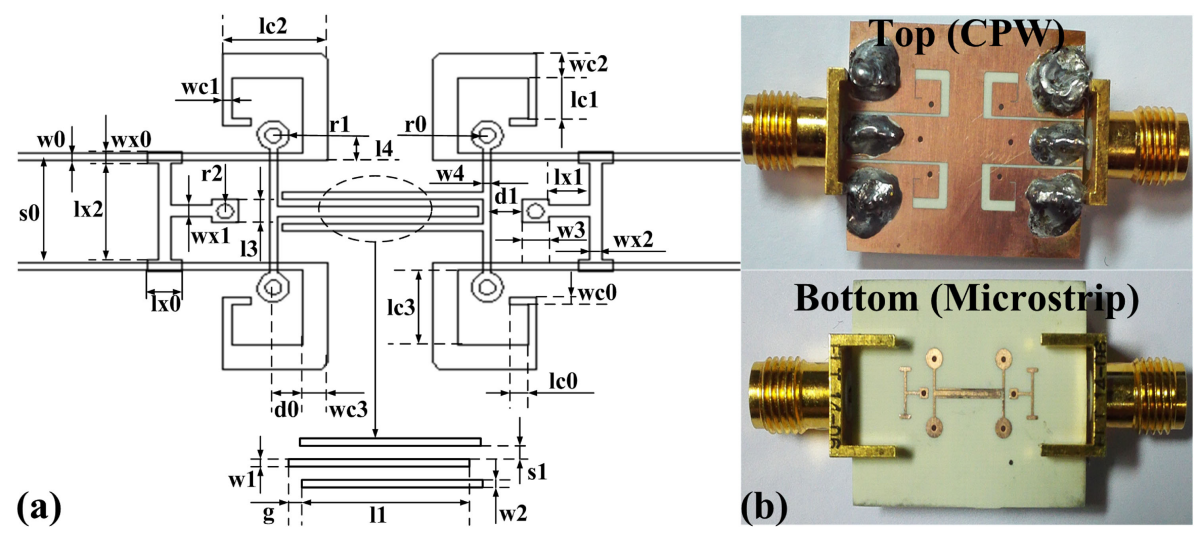

Fig. 5. (a) Dimensions of the UWB BPF, (b) Picture of the fabricated UWB BPF.

The final dimensions of the fabricated filter optimized by HFSS 13 are (see Fig. $5(\mathrm{a})): \mathrm{w}_{0}=0.24 \mathrm{~mm}, \mathrm{~s}_{0}=3.5 \mathrm{~mm}, \quad \mathrm{wx}_{0}=0.3 \mathrm{~mm}, \quad 1 \mathrm{x}_{2}=3.44 \mathrm{~mm}, \quad 1 \mathrm{x}_{0}=$ $1.1 \mathrm{~mm}, \quad \mathrm{wx}_{1}=0.2 \mathrm{~mm}, \quad \mathrm{r}_{2}=0.25 \mathrm{~mm}, \quad 1_{3}=0.8 \mathrm{~mm}, \quad \mathrm{wc}_{1}=0.1 \mathrm{~mm}, \quad \mathrm{lc}_{2}=$ $3.32 \mathrm{~mm}, \quad \mathrm{rl}=0.8 \mathrm{~mm}, \quad \mathrm{~d}_{0}=0.9 \mathrm{~mm}, \quad \mathrm{wc}_{3}=0.82 \mathrm{~mm}, \quad \mathrm{l}_{4}=0.97 \mathrm{~mm}, \quad \mathrm{w} 1=$ $0.35 \mathrm{~mm}, \mathrm{w}_{2}=0.1 \mathrm{~mm}, \mathrm{~s}_{1}=0.1 \mathrm{~mm}, \mathrm{l}_{1}=6.2 \mathrm{~mm}, \mathrm{~g}=0.15 \mathrm{~mm}, \mathrm{r}_{0}=0.25 \mathrm{~mm}$, $\mathrm{w}_{4}=0.2 \mathrm{~mm}, \mathrm{~d}_{1}=0.5 \mathrm{~mm}, \mathrm{w}_{3}=0.8 \mathrm{~mm}, 1 \mathrm{x}_{1}=1.3 \mathrm{~mm}, 1 \mathrm{c}_{3}=2.6 \mathrm{~mm}, 1 \mathrm{c}_{0}=$ $0.6 \mathrm{~mm}, \mathrm{wc}_{0}=0.1 \mathrm{~mm}, \mathrm{lc}_{1}=1.4 \mathrm{~mm}, \mathrm{wc}_{2}=0.82 \mathrm{~mm}, \mathrm{wx}_{2}=0.2 \mathrm{~mm}$.

As shown in Fig. 6, the results of the fabricated filter are obtained by vector network analyzer E8363B. The measured results show that this filter achieves a very wide fractional bandwidth of $133 \%(2.35-11.75 \mathrm{GHz})$ with good return loss (better $15 \mathrm{~dB}$ within $2.8-11.1 \mathrm{GHz}$ except the notched band). Besides, in most passband $(3-10 \mathrm{GHz})$, the insertion loss is less than $0.6 \mathrm{~dB}$. Obviously, sharp selectivity is achieved that the selectivity factory ( $\mathrm{S} . \mathrm{F}=\Delta \mathrm{f}|3 \mathrm{~dB} / \Delta \mathrm{f}| 30 \mathrm{~dB}$ ) is 0.83 . Moreover, a notched band with a maximum rejection loss of $42 \mathrm{~dB}$ at $8.2 \mathrm{GHz}$ is obtained. And the group delay is relatively flat with a variation of no more than $0.1 \mathrm{~ns}$ in the whole UWB passband not including the notched band. 


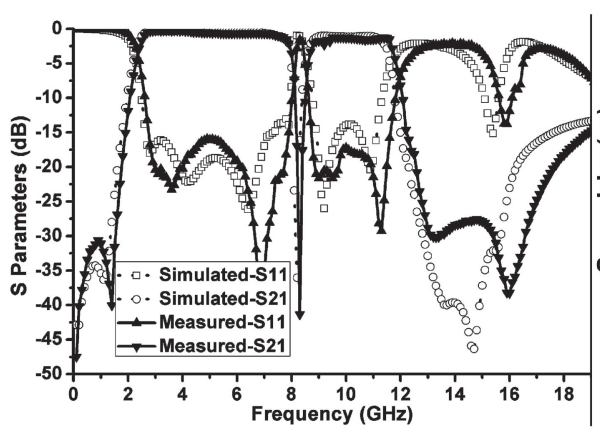

(a)

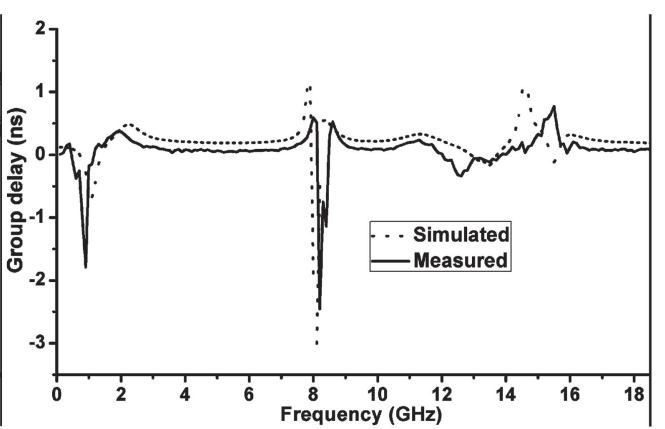

(b)

Fig. 6. Simulated and measured results (a) S parameters, (b) Group delay.

Table I. Comparison results between the proposed filter and others

\begin{tabular}{|c|c|c|c|c|c|c|c|}
\hline Ref. & S.F & $\mathbf{3 ~ d B}$ & $\begin{array}{c}|\mathbf{S 1 1}| \\
\mathbf{f B W}\end{array}$ & $\begin{array}{c}|\mathbf{S 2 1}| \\
(\mathbf{d B})\end{array}$ & $\begin{array}{c}\mathbf{F c} \\
(\mathbf{G H z})\end{array}$ & $\begin{array}{c}\mathbf{N B} / \mathbf{A} \\
(\mathbf{G H z} / \mathbf{d B})\end{array}$ & $\begin{array}{c}\text { Size } \\
\left(\lambda_{\mathrm{g}} \times \lambda_{\mathrm{g}}\right)\end{array}$ \\
\hline$[1]$ & 0.88 & $108 \%$ & $>10$ & $\mathrm{NG}$ & 12.6 & $5.7 / 10.3$ & $1.12 \times 0.84$ \\
{$[3]$} & 0.60 & $116 \%$ & $>15$ & $<0.7$ & 14 & $6.0 / 17.0$ & $0.51 \times 0.45$ \\
{$[4]$} & 0.90 & $117 \%$ & $>11.5$ & $<1.2$ & 15 & $\mathrm{No}$ & $0.25 \times 0.36$ \\
{$[5]$} & 0.77 & $119 \%$ & $>16$ & $<0.41$ & 12 & $\mathrm{No}$ & $0.72 \times 1.11$ \\
{$[6]$} & 0.80 & $118 \%$ & $>11.5$ & $<1.0$ & 13.6 & $5.6 / 19.7$ & $0.98 \times 0.35$ \\
{$[7]$} & 0.54 & $103 \%$ & $>12.5$ & $<0.45$ & $\mathrm{NG}$ & $7.0 / 20.0$ & $0.75 \times 0.40$ \\
{$[8]$} & 0.80 & $114 \%$ & $>10$ & $<0.83$ & 14.5 & $5.5 / 22.0$ & $1.14 \times 0.90$ \\
{$[9]$} & $\mathrm{NG}$ & $113 \%$ & $>14.9$ & $<1.77$ & $\mathrm{NG}$ & $5.8 / 17.9$ & $0.87 \times 0.66$ \\
{$[10]$} & 0.74 & $109 \%$ & $>10$ & $<1.5$ & 27.6 & $5.2 / 18.0$ & $0.82 \times 0.50$ \\
{$[11]$} & 0.72 & $110 \%$ & $>11$ & $<0.6$ & 15.6 & $8.1 / 18.0$ & $0.68 \times 0.50$ \\
This & 0.83 & $133 \%$ & $>15$ & $<0.7$ & 18 & $8.2 / 42.0$ & $0.58 \times 0.47$ \\
Work & & & & & & & \\
\hline
\end{tabular}

S.F.: selectivity factor; $\left.\Delta \mathrm{f}\right|_{3 \mathrm{~dB}},\left.\Delta \mathrm{f}\right|_{30 \mathrm{~dB}}: 3 \mathrm{~dB}$ and $30 \mathrm{~dB}$ bandwidth; $\mathrm{Fc}$ : the upper stopband frequency with $20-\mathrm{dB}$ attenuation; $\lambda_{\mathrm{g}}$ : the guided wavelength at $6.85 \mathrm{GHz}$; NB: Notched band; A: Attenuation; NG: Not given.

As shown in Table I, the proposed filter not only has good in-band (lower insertion loss and good return loss) but also good out-of-band characteristics (sharp selectivity and relatively wide stopband). Moreover, the notched band is really deep and it is controllable.

\section{Conclusions}

In this letter, a novel UWB BPF based on CPW-MS-CPW is proposed and fabricated. Its selectivity is improved significantly by introducing ICL and SRR. Moreover, a deep notched band with maximum attenuation of $42 \mathrm{~dB}$ at $8.2 \mathrm{GHz}$ is implemented by a coupling T-shaped short stub (CTSSS), and the notched band (centre frequency, bandwidth and attenuation) is controllable with little influence on other characteristics of the proposed UWB BPF. The measured results show that the proposed filter performs satisfactory performance such as good selectivity, good return loss $(>15 \mathrm{~dB})$ and wide bandwidth $(2.35$ to $11.75 \mathrm{GHz})$, which make the proposed filter can be well applied in UWB systems.

\section{Acknowledgments}

The work is supported by National Natural Science Foundation of China (61271034). 